\title{
The biological activities of Arabis alpina L. subsp. brevifolia (DC.) Cullen against food pathogens
}

https://doi.org/10.1515/chem-2018-0104

received February 15, 2018; accepted June 23, 2018.

Abstract: In this study, in vitro biological activities of both methanol and ethanol extracts of Arabis alpina subsp. brevifolia were investigated. Also, the phenolic components of this plant was examined in this study. The extracts were tested against the eight strains of food pathogens for their antimicrobial activities by utilizing minimum inhibitory concentration (MIC) and disc diffusion assay. The non-enzymatic antioxidant activities were determined according to scavenging of the free radical 2,2-diphenyl-1-picrylhydrazyl (DPPH). The phenolic compounds were analyzed by high performance liquid chromatography (HPLC). The main component was ellagic acid for the methanol extract of stem-leaf, rutin for the ethanol extract of stem-leaf, and 2,5-dihydroxybenzoic acid for the methanol and ethanol extracts of fruit-flower. The ethanolic extracts of leaves revealed antibacterial activities against Salmonella Typhimurium $(7 \mathrm{~mm})$ while the ethanolic extracts of flowers demonstrated no activity against the test pathogens. The methanolic extracts of leaf-flower showed antibacterial activities against $S$. Typhimurium $(7 \mathrm{~mm})$. No activity was observed against $C$. albicans. The MIC value for four test bacteria was 13000 $\mu \mathrm{g} / \mathrm{mL}$. The ethanol extracts of $A$. alpina subsp. brevifolia exhibited the highest DPPH inhibition (76\%). This study showed that A. alpina subsp. brevifolia possesses antioxidant and antimicrobial activities.

Keywords: Arabis; Antimicrobial activity; Antioxidant activity; Food-borne pathogens; HPLC.

\section{Introduction}

The Brassicaceae family is one of the broad-spreaded and richly diverse families within the plant kingdom and

\footnotetext{
*Corresponding author: N. Balpinar, Department of Biology, Faculty of Arts and Science, Mehmet Akif Ersoy University, Burdur 15030, Turkey, E-mail: nerdogan@mehmetakif.edu.tr
}

contains many species (Arabidopsis, Brassica, Boechera, Thellungiella, Camelina, Raphanus and Arabis) that have economic, scientific and agricultural importance [1-3]. This family comprises 49 tribes, 325 genera and 3740 species which mainly spread in the temperate region of the world, and Turkey is extremely rich in terms of the diversity of this family, as well [4-6]. In the family, the genus of Arabis L. containing about 60 species is represented by 17 species in the Flora of Turkey and the East Aegean Islands and by 22 species (24 taxa) in Turkey [7-9]. Arabis alpina L. in the mountain habitats of Anatolia, which is distributed on the alpine habitats, so named alpine rock-cress, emerges as model species in the ecological and evolutionary researches which have been conducted in recent years $[10,11]$. As a perennial herb, A. alpina L. subsp. brevifolia (DC.) Cullen is one of the two subspecies (brevifolia and caucasica) and generally grows on rocks and screes in Turkey [12].

Brassicaceae family has received a great deal of attention in recent years because of its antioxidative and antimicrobial properties [13-16]. It is one of the most studied family due to its rich phytochemical contents [17]. They have great importance in terms of preventing oxidative damage [18] and diseases like cancer, Alzheimer's and Parkinson's [19]. Karakoca et al. [20] report high chlorogenic acid in the methanolic root extract of Isatis floribunda, which is used to reduce the relative risk of cardiovascular disease, diabetes mellitus, and Alzheimer's disease [21-23]. Ethanol extracts of the leaf and seed of Eruca sativa have shown anti-secretory, cytoprotective, and anti-ulcer effects against gastric lesions [24]. Recent studies have indicated that the essential oils of the rootstem-leaf-fruit of Eruca vesicaria subsp. longirostris have shown significant antimicrobial activity against $S$. aureus, B. subtilis, B. amyloliquefaciens, E. coli, P. aeruginosa, S. enterica, and C. albicans [25]. Similarly, Rani et al. [26] report that the crude water extracts of the seed of Eruca sativa posses highest antibacterial activity against Enterobacter agglomerans and Hafnia alvei.

In scope of my knowledge, the present study is the first attempt to investigate A. alpina L. subsp. brevifolia (DC.) Cullen. The objectives of this study are to determine the 
phenolic compound composition of this plant, to examine antimicrobial activities of the various extracts of aboveground organs (leaf, flower) of the plant against various food pathogens, and to determine antioxidant capacity of the extracts.

\section{Methods}

\subsection{Plant material}

The samples of A. alpina subsp. brevifolia were collected from Burdur/Turkey $\left(37^{\circ} 41^{\prime} 44.82^{\prime \prime} \mathrm{N}, 30^{\circ} 20^{\prime} 43.50^{\prime \prime} \mathrm{E}\right.$; $1157 \mathrm{~m}$ asl.) in its blooming season in May 2015. The identification of the specimens was made according to Flora of Turkey and the East Aegean Islands [12,27], and the samples were deposited at the Botanical Research Laboratory of the Biology Department, Mehmet Akif Ersoy University (voucher number: Balpinar, 1551).

\subsection{Microorganisms}

In order to specify in vitro antimicrobial activities, the following food pathogens were utilized in this study: Bacillus subtilis RSKK245, Candida albicans RSKK02029, Escherichia coli ATCC11229, Enterococcus faecalis ATCC8093, Listeria monocytogenes ATCC7644, Salmonella Typhimurium RSKK19, Staphylococcus aureus RSKK2392 and Yersinia enterocolitica NCTC11174. These microorganisms were supplied from ATCC (American Type Culture Collection, USA), RSKK (Refik Saydam National Type Culture Collection, Turkey) and NCTC (North Central Texas College, USA).

\subsection{Cultivation of microorganisms}

Among these food-borne pathogens, the yeast $C$. albicans was cultivated in Sabouraud Dextrose agar plates (SDA, Merck) at $30^{\circ} \mathrm{C}$ for $24 \mathrm{~h}$, and the other bacteria were in Mueller-Hinton agar plates (MHA, Merck) at $37^{\circ} \mathrm{C}$ for $24 \mathrm{~h}$.

\subsection{Extraction process}

The above-ground organs of plant were washed 2-3 times in running water and once in sterile water. The plant materials were divided into their pieces (stem, leaf and flower). Next, they were air-dried and milled by using a blender. The homogenized fine powder was stored at $4^{\circ} \mathrm{C}$ in a room which is away from natural sunlight until extraction process. These materials ( $40 \mathrm{~g}$ ) were extracted separately in a soxhlet apparatus (Isotex) with $250 \mathrm{ml}$ methanol and ethanol solvents. Time of extraction process was 4-8 $\mathrm{h}$. The purpose of preparing both methanol and ethanol extracts of the plant is that the presence of polar groups (e.g. phenolics, alcoholoids etc.) which shows antimicrobial activity and are highly soluble in these two solvents. The obtained extracts were evaporated by using an evaporator and transferred into the sterilized falcon tubes which contain their own solvents (i.e. the material extracted in methanol was placed in falcon tubes containing methanol; the material extracted in ethanol was transferred in the tubes containing ethanol). The extracts prepared in the concentration of $200 \mathrm{mg} / \mathrm{ml}$ were kept under refrigerated conditions until the analysis.

\subsection{HPLC analysis of phenolic compounds in the extracts}

The HPLC analysis (described by Caponio et al. [28]) that was slightly modified was used to determine phenolic components. A modular Shimadzu Prominence Auto Sampler (SIL 20 ACHT) HPLC system (Shimadzu, Kyoto, Japan) comprised of a LC-20AT pump, a CTO-10ASVp column oven, a SPD-M20A DAD detector, a 20ACBM interface was utilized in the analysis. The flow rate of run was maintained at $0.8 \mathrm{~mL} / \mathrm{min}$, and the detection wavelength was $240 \mathrm{~nm}$ for ellagic acid, $260 \mathrm{~nm}$ for epicatechin, $280 \mathrm{~nm}$ for gallic acid, 3,4-dihydroxybenzoic, 4-hydroxybenzoic, caffeic, cinnamic acids and naringin, $320 \mathrm{~nm}$ for 2,5-dihydroxybenzoic, chlorogenic, vanillic, $\mathrm{p}$-coumaric, ferulic acids, and $360 \mathrm{~nm}$ for rutin and quercetin. A Zorbax Eclipse XDB-C18 $(4.6 \times 250 \mathrm{~mm}) 5$ $\mu \mathrm{m}$ column was used and its temperature was $40^{\circ} \mathrm{C}$. The separation was executed by using a gradient program with a two-solvent system (solution A was 3\% formic acid, solution B was methanol). Injection volume was $100 \mu \mathrm{L}$. Data were acquired by Shimadzu LC Solution software.

\subsection{In vitro antimicrobial assay}

In order to determine antimicrobial activities, disc diffusion assay was used. The organic solvents of this study were ethanol and methanol. The turbidity of the active cultures was equalled to 0.5 McFarland $\left(1.5 \times 10^{8}\right.$ $\mathrm{cfu} / \mathrm{mL}$ ), and then they were inoculated to the plates $(0.1 \mathrm{ml})$ under aseptic conditions. The plant extracts (45 
$\mu \mathrm{L}$ from $200 \mathrm{mg} / \mathrm{mL}$ concentration) were ingrained into blank discs $(6 \mathrm{~mm})$ and they were placed on plate surface. After the incubation, the diameter of inhibition zones was measured in millimeters. The solvents of extraction (ethanol and methanol) were defined as negative control group while ampicillin $(10 \mu \mathrm{g})$, tetracycline $(30 \mu \mathrm{g})$ and nystatin $(100 \mu \mathrm{g})$ were used as positive control group [29]. All measurements were performed in triplicate parallel cultures, and the values obtained were given in average.

\subsection{Determination of minimal inhibitory concentration}

Broth dilution method was employed for determination of MIC values of the extracts. The active culture concentrations were standardized to $0.5 \mathrm{McF}$ Farland and all experiments were conducted in $2 \mathrm{~mL}$ Mueller-Hinton Broth. Serial dilutions, each of their concentrations was $13000 ; 6500 ; 3250 ; 1625 ; 812.5 \mu \mathrm{g} / \mathrm{mL}$, were prepared, and the same amounts of active cultures $(100 \mu \mathrm{L})$ were inoculated into each of them [30,31]. After incubation at $37^{\circ} \mathrm{C}$ for $24 \mathrm{~h}$ and the lowest concentration was defined as MIC value.

\subsection{Non-enzymatic antioxidant assay}

The determination of antioxidant activity was accomplished by using DPPH radical scavenging assay. The absorbance of the extracts was measured at a wavelength of $515 \mathrm{~nm}$ in an UV/Vis spectrophotometer (Optizen POP, Korea) [32]. The methanol DPPH solution was used as control. Trolox (6-hydroxy-2,5,7,8-tetramethychroman-2carboxylic acid; Sigma) was used as reference standard and the results were given through the equivalent of $\mathrm{mM}$ Trolox/g DW (TE).

Ethical approval: The conducted research is not related to either human or animal use.

\section{Results}

The analysis of phenolic acid compounds in A. alpina subsp. brevifolia was performed utilizing the HPLC technique. A total of 15 phenolic standards were used and 14 phenolic components were determined in this study (Table 1). The results of the analysis showed that the major components were ellagic acid, which was followed by rutin, caffeic acid and epicatechin, for the methanolic
Table 1: Phenolic compositions of the various extracts from A. alpina subsp. brevifolia.

\begin{tabular}{lllll}
\hline \multicolumn{5}{l}{$\begin{array}{l}\text { The various extracts of } \text { A. alpina subsp. } \\
\text { brevifolia }(\mu \mathrm{g} / \mathrm{mg})\end{array}$} \\
\hline Phenolic compounds & $\mathrm{A}$ & $\mathrm{B}$ & $\mathrm{C}$ & $\mathrm{D}$ \\
Gallic acid & 0.96 & 2.91 & 3.14 & 1.96 \\
$\begin{array}{l}\text { 3,4-dihydroxybenzoic } \\
\text { acid }\end{array}$ & 0.65 & 2.69 & 3.4 & 2.25 \\
$\begin{array}{l}\text { 4-hydroxybenzoic } \\
\text { acid }\end{array}$ & 2.71 & 5.98 & 19.19 & 20.62 \\
$\begin{array}{l}\text { 2,5-dihydroxybenzoic } \\
\text { acid }\end{array}$ & 141.76 & 353.33 & $1458 . .09$ & 14672.68 \\
Chlorogenic acid & 7.73 & 24.23 & 32.7 & 83.22 \\
Vanillic acid & 49.79 & 110.08 & 124.71 & 109.14 \\
Epicatechin & 212.86 & 73.01 & 663.83 & 136.25 \\
Caffeic acid & 278.37 & 315.72 & 847.90 & 543.91 \\
p-coumaric acid & $(\mathrm{nd})$ & $(\mathrm{nd})$ & (nd) & (nd) \\
Ferulic acid & 8.07 & 12.04 & 1.23 & 0.01 \\
Rutin & 300.43 & 1238.77 & 582.93 & (nd) \\
Ellagic acid & 319.01 & 493.19 & 726.41 & 157.09 \\
Naringin & 119.60 & 167.27 & 32.80 & 267.31 \\
Cinnamic acid & 25.09 & 17.98 & 6.72 & 13.30 \\
Quercetin & 131.374 & 155.39 & 289.904 & 322.974 \\
\hline & & & &
\end{tabular}

A: methanol stem-leaf extract, B: ethanol stem-leaf extract, C: methanol fruit-flower extract, D: ethanol fruit-flower extract, (nd): not determined

stem-leaf extract, rutin for the ethanolic stem-leaf extract, 2,5-dihydroxybenzoic acid for the methanolic fruit-flower extract, and 2,5-dihydroxybenzoic acid for the ethanolic fruit-flower extract. The chromatogram for the standards and the HPLC chromatograms of the various extracts are shown in Figure 1 and Figure 2, respectively.

Using disc diffusion assay, which it was utilized as a method for determining antimicrobial activity in this study, it was determined whether the various extracts of some parts of A. alpina subsp. brevifolia would show activity or not against the food-borne pathogens by measuring their inhibition zone. The results indicated that no activity was observed in the ethanol extract of the flowers while the ethanol extract of the leaves revealed antibacterial activities against $S$. Typhimurium RSKK19 (7 $\mathrm{mm})$. The methanol extracts of the leaves and the flowers showed antibacterial activities against $S$. Typhimurium RSKK19 (7 mm). Moreover, neither ethanol nor methanol extracts of the plant parts exhibited antifungal activity against $C$. albicans RSKK02029. The results are illustrated in Table 2. 


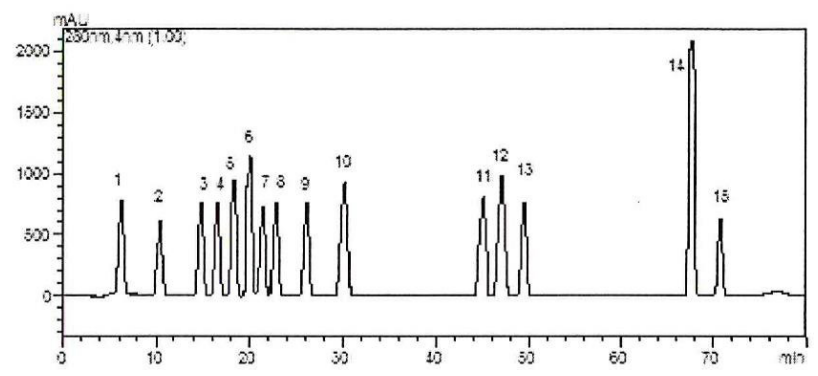

Figure 1: Standard chromatogram; 1 = gallic acid, $2=$ 3,4-dihydroxybenzoic acid, 3 = 4-hydroxybenzoic acid, 4 = 2,5-dihydroxybenzoic acid, 5 = chlorogenic acid, 6 = vanillic acid, 7 = epicatechin, 8 = caffeic acid, $9=$ p-coumaric acid, $10=$ ferulic acid, 11 = rutin, 12 = ellagic acid, 13 = naringin, 14 = cinnamic acid, $15=$ quercetin.

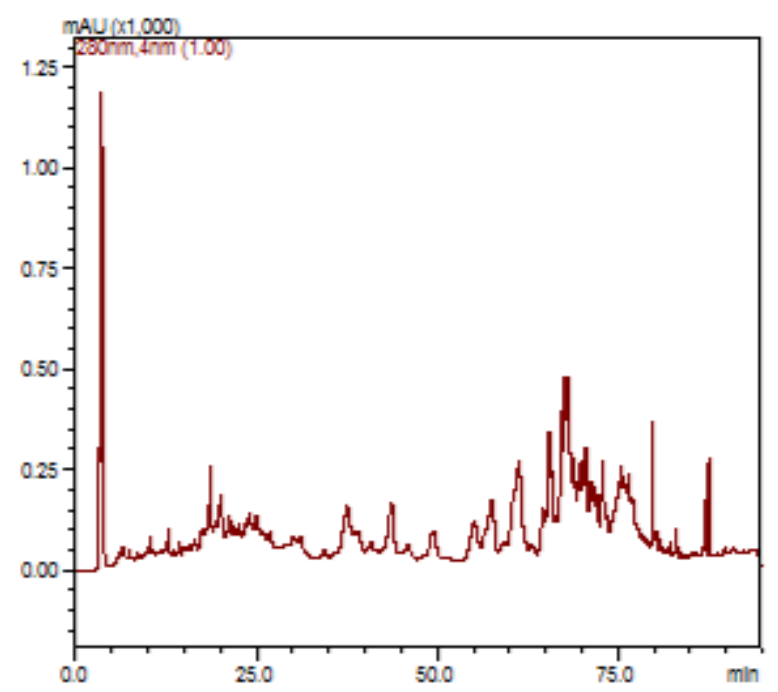

(a)

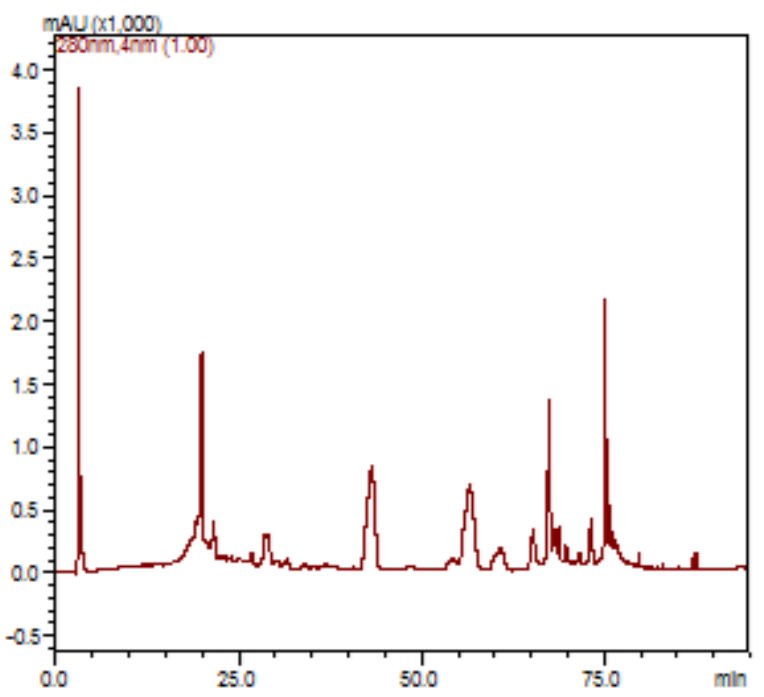

(c)
The other test applied in this study was MIC which was conducted in order to determine the antibacterial activity [30,31]. According to the results, the MIC value of A. alpina subsp. brevifolia extracts was determined to be $13000 \mu \mathrm{g} / \mathrm{mL}$ (Table 3).

In order to characterize the non-enzymatic antioxidant activities of the plant extracts, DPPH assay was used. The highest DPPH scavenging capacity was $76.3 \%$ in the ethanol extracts of the flowers-fruits-seeds of $A$. alpina subsp. brevifolia. Its trolox equivalent was $2.134 \mathrm{mM} / \mathrm{g}$ DW (Table 4).

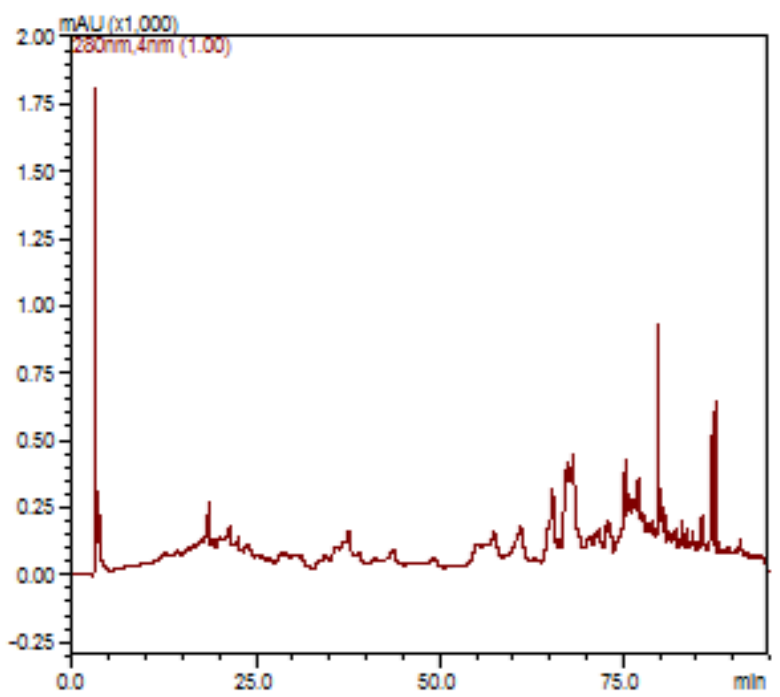

(b)

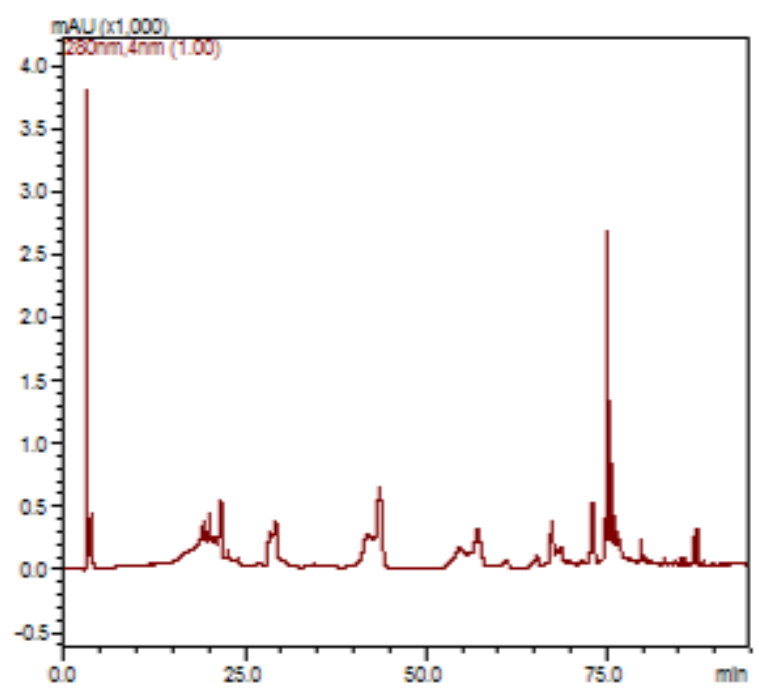

(d)

Figure 2: HPLC chromatograms of $A$. alpina subsp. brevifolia. a: methanol stem-leaf extract, b: ethanol stem-leaf extract, c: methanol fruitflower extract, d: ethanol fruit-flower extract. 
Table 2: Antimicrobial activities of A. alpina subsp. brevifolia against food-borne pathogens $(200 \mathrm{mg} / \mathrm{mL})$.

\begin{tabular}{|c|c|c|c|c|c|c|c|}
\hline \multirow[b]{4}{*}{ Microorganisms } & \multicolumn{7}{|c|}{ Inhibition zone $(\mathrm{mm})$} \\
\hline & \multicolumn{4}{|c|}{ Extracts of Plant Parts } & \multicolumn{3}{|l|}{ Antibiotics } \\
\hline & Leaf & Flower & Leaf & Flower & TE & NS & A \\
\hline & Ethanol & & Methanol & & & & \\
\hline Bacillus subtilis RSKK 245 & $(-)$ & $(-)$ & $(-)$ & $(-)$ & nt & $\mathrm{nt}$ & $10 \pm 0.001$ \\
\hline Staphylococcus aureus RSKK2392 & $(-)$ & $(-)$ & $(-)$ & $(-)$ & nt & nt & $10 \pm 0.001$ \\
\hline Salmonella Typhimurium RSKK19 & $7 \pm 0.01$ & $(-)$ & $7 \pm 0.01$ & $7 \pm 0.01$ & $14 \pm 0.001$ & $\mathrm{nt}$ & nt \\
\hline Enterococcus faecalis ATCC 8093 & $(-)$ & $(-)$ & $(-)$ & $(-)$ & nt & $\mathrm{nt}$ & - \\
\hline Escherichia coli ATCC11229 & $(-)$ & $(-)$ & $(-)$ & $(-)$ & $14 \pm 0.001$ & nt & nt \\
\hline Listeria monocytogenes ATCC7644 & $(-)$ & $(-)$ & $(-)$ & $(-)$ & nt & nt & $12 \pm 0.001$ \\
\hline Yersinia enterocolitica NCTC11174 & $(-)$ & $(-)$ & $7 \pm 0.01$ & $(-)$ & $20 \pm 0.001$ & nt & $\mathrm{nt}$ \\
\hline Candida albicans RSKK02029 & $(-)$ & $(-)$ & $(-)$ & $(-)$ & nt & $7 \pm 0.001$ & nt \\
\hline
\end{tabular}

(-): no inhibition, nt: not tested, TE: tetracycline $(30 \mu \mathrm{g}), \mathrm{NS}$ : nystatin $(100 \mu \mathrm{g}), \mathrm{A}$ : ampicillin $(10 \mu \mathrm{g})$

Table 3: Minimum inhibitory concentrations of $A$. alpina subsp. brevifolia $(\mu \mathrm{g} / \mathrm{mL})$.

\begin{tabular}{|c|c|c|c|c|}
\hline Microorganisms & LE & $\mathrm{FE}$ & LM & FM \\
\hline $\begin{array}{l}\text { Salmonella } \\
\text { Typhimurium RSKK19 }\end{array}$ & 13000 & (nt) & 13000 & 13000 \\
\hline $\begin{array}{l}\text { Yersinia enterocolitica } \\
\text { NCTC11174 }\end{array}$ & (nt) & (nt) & 13000 & (nt) \\
\hline
\end{tabular}

LE: leaf ethanol extract, FE: flower ethanol extract, LM: leaf methanol extract, FM: flower methanol extract, (nt): not tested

Table 4: DPPH radical scavenging activities of $A$. alpina subsp. brevifolia extracts.

\begin{tabular}{lllll}
\hline $\begin{array}{l}\text { Radical scavenging } \\
\text { activity }\end{array}$ & \multicolumn{2}{l}{$\begin{array}{l}\text { Stem-Leaf } \\
\text { Ethanol }\end{array}$} & Methanol & \multicolumn{2}{l}{ Fthaner-Fruit-Seed } \\
& 0 & 70.0 & 76.3 & 74.7 \\
\hline DPPH (\%) & 0 & 1.96 & 2.1 & 2.06 \\
$\begin{array}{l}\text { Trolox equivalent } \\
\text { (mM/g DW) }\end{array}$ & 0 & & & \\
\hline
\end{tabular}

DW: dry weight

\section{Discussion}

The present analysis showed the presence of tannins (ellagic acid, epicatechin), flavonoids (rutin) and phenolic acids (caffeic acid, 2,5-dihydroxybenzoic acid) in various extracts of the different parts of A. alpina subsp. brevifolia (Table 1). Recent pharmacological studies on tannins have revealed that they have antibacterial [33,34], anticarcinogenic [35], and antioxidant [36,37] properties. Flavonoids have been previously associated with antioxidant properties [38]. Among all phenolic compounds identified in A. alpina subsp. brevifolia, 2,5-dihydroxybenzoic acid showed the highest level, and it has remarkable antioxidant characteristics against oxidative stress [39].

Because of its economic value, Brassicaceae has been in the centre of attraction among the studies of antimicrobial activity. For instance, Razavi et al. [40] and Esmaeili et al. [19] reported there were 27.7 and 20 $\mathrm{mm}$ zones for $B$. subtilis in the methanol extracts of Crambe orientalis (Brassicaceae) and Malcolmia africana (Brassicaceae), respectively. Moreover, Razavi et al. [40] reported the presence of $23 \mathrm{~mm}$ activity zone for $E$. coli while Esmaeili et al. [19] found no activity against the same bacteria. In the studies by Karakoca et al. [20] regarding the flower ethanol extracts of Isatis floribunda (Brassicaceae), it was detected $12.9 \mathrm{~mm}$ activity zone for S. aureus and $13.5 \mathrm{~mm}$ for E. coli. In the present study, 7 $\mathrm{mm}$ zone was obtained against the gram negative bacteria $S$. Typhimurium while there was no activity against $E$. coli. However, these bacteria are more complex regarding the structure of cell membrane in comparison to the gram positive bacteria [25]. Generally it was difficult to determine striking antimicrobial activity against Gram negative bacteria. Another study supports my results. For example, Esmaeili et al. [19] found no inhibition zone against the second Gram negative bacteria at issue.

The results of this study showed that the MIC value was $13000 \mu \mathrm{g} / \mathrm{mL}$ both in the ethanolic extracts of the leaves and the methanolic extracts of flowers against $S$. 
Typhimurium RSKK19 and in the methanolic extracts of the leaves against $Y$. enterocolitica NCTC11174. In the studies of Crambe orientalis (Brassicaceae), this value was measured as $500 \mu \mathrm{g} / \mathrm{mL}$ for $E$. coli by Razavi et al. [40]. MIC result of this study is higher than Razavi's result. The possible reason of their finding may come from a phytochemical called isothiocyanates which is responsible for some biological activities [40]. Grosso et al. [41] found the MIC value of $125 \mathrm{mg} / \mathrm{mL}$ in the methanol extracts of Capsella bursa-pastoris for S. Typhimurium and $E$. coli. The MIC result of this study is better than the result of Grosso et al. [41].

In this study, the highest inhibitory percentage of DPPH was $76.3 \%$ and the trolox equivalent was 2.1 $\mathrm{mM} / \mathrm{g}$ DW. The highest DPPH scavenging activity was determined by Karakoca et al. [20] in the flower extracts of Isatis floribunda (89.6\%). Omri et al. [25] recorded the radical activity as $56.3 \%$ in the leaf extracts and $83.6 \%$ in the fruit extracts of Eruca vesicaria subsp. longirostris. These results are similar to result of the present study. The studies conducted on the members of Brassicaceae family report that there is a high correlation between antioxidant activity and polyphenolic contents [25].

In the present study, the phenolic components of A. alpina subsp. brevifolia is reported for the first time. It indicates that this species is an interesting source of polyphenols and phenolic acids. This study is also the first attempt in utilizing antimicrobial tests on the various extracts of the different body parts (leaf, flower) of $A$. alpina subsp. brevifolia. Besides, it differs from the others in terms of the variety of bacteria used in the tests. The findings obtained in this research reveal that the extracts of the leaves of A. alpina subsp. brevifolia generally indicate higher antimicrobial activity than the extracts of the flowers, and that the extracts of the flower-fruit-seed of this plant have a high antioxidant capacity (Table 2 and 4). The data of this study indicate that A. alpina subsp. brevifolia may be used as a potential source of natural antioxidant and antibacterial agents. Nevertheless, I am of the opinion that Brassicaceae family, which is rich in isothiocynate derivatives, should be further investigated in in vivo and in vitro studies.

Acknowledgments: This study was supported by Mehmet Akif Ersoy University Scientific Research Projects Coordination Unit (No. 0338-NAP-16). No sponsors have got involved in any stage of the study; which are collection, analysis and interpretation of data, and manuscripting of the study and making decision on publishing the results. The author thanks Assoc. Prof. Dr. Gulten OKMEN for her contributions in the laboratory studies.
The HPLC analysis of phenolic compounds in the extracts was conducted in Scientific and Technological Research and Application Center at Mehmet Akif Ersoy University (Burdur-Turkey); (Protocol no: E.5045).

Conflict of interest: Authors state no conflict of interest.

\section{References}

[1] Anjum N.A., The plant family Brassicaceae: An introduction, In: Anjum N.A., Ahmad I., Pereira M., Duarte A., Umar S., Khan N. (Eds.), The plant family Brassicaceae, vol. 21, Springer, Dordrecht, 2012.

[2] Hohmann N., Wolf E.M., Lysak M.A., Koch M.A., A timecalibrated road map of Brassicaceae species radiation and evolutionary history, The Plant Cell, 2015, 27, 2770-2784.

[3] Lopez L., Wolf E.M., Pires J.C., Edger P.P., Koch M.A., Molecular resources from transcriptomes in the Brassicaceae family, Frontiers in Plant Science, 2017, 8, 1488.

[4] Al-Shehbaz I.A., A generic and tribal synopsis of the Brassicaceae (Cruciferae), Taxon, 2012, 61, 931-954.

[5] Kiefer M., Schmickl R., German D.A., Mandáková T., Lysak M.A., Al-Shehbaz I.A., et al., BrassiBase: Introduction to a novel knowledge database on Brassicaceae evolution, Plant Cell Physiol., 2013, 55, 1-9.

[6] Dönmez A., Aydın Z.U., Koch M.A., Aubrieta alshehbazii (Brassicaceae), a new species from Central Turkey, Phytotaxa, 2017, 299, 103-110.

[7] Koch M.A., Karl R., Kiefer C., Al-Shehbaz I.A., Colonizing the American continent: Systematics of the genus Arabis in North America (Brassicaceae), Am. J. Bot., 2010, 97, 1040-1057.

[8] Mutlu B., Erik S., Distribution maps and new IUCN threat categories for the genus of Arabis, Pseudoturritis and Turritis (Brassicaceae) in Turkey, Hacettepe J. Biol. \& Chem., 2015, 43, 133-143.

[9] Özüdoğru S., Fırat M., Arabis watsonii (P.H. Davis) F.K. Mey.: An overlooked cruciferous species from eastern Anatolia and its phylogenetic position, PhytoKeys, 2016, 75, 57-68.

[10] Toräng P., Wunder J., Obeso J.R., Herzog M., Coupland G., Ågren J., Large scale adaptive differentiation in the alpine perennial herb Arabis alpina, New Phytol., 2015, 206, 459-470.

[11] Pavlova D., Laporte F., Ananiev E.D., Herzog M., Pollen morphological studies on Arabis alpina L. (Brassicaceae) populations from the alps and the Rila mountains, Genet. Plant Physiol., 2016, 6, 27-42.

[12] Cullen J., Arabis L., In: Davis P.H.(Eds.), Flora of Turkey and the East Aegean Islands, volume 1, Edinburgh University Press, Edinburgh, 1965.

[13] Cartea M.E., Francisco M., Soengas P., Velasco P., Phenolic compounds in Brassica vegetables, Molecules, 2010, 16, 251280.

[14] Koubaa M., Driss D., Bouaziz F., Ghorbel R.E., Chaabouni S.E., Antioxidant and antimicrobial activities of solvent extract obtained from rocket (Eruca sativa L.) flowers, Free Radicals \& Antioxidants, 2015, 5, 29-34. 
[15] Alqahtani F.Y., Aleanizy F.S., Mahmoud A.Z., Farshori N.N., Alfaraj R., Al-sheddi E.S., et al., Chemical composition and antimicrobial, antioxidant, and anti-inflammatory activities of Lepidium sativum seed oil, Saudi J. Biol. Sci., 2018, https://doi. org/10.1016/j.sjbs.2018.05.007.

[16] Rashid M.A., Akhtar M.N., Ashraf A., Nazir S., ljaz A., Omar N.A., et al., Chemical composition and antioxidant, antimicrobial and haemolytic activities of Crambe cordifolia roots, Farmacia, 2018, 66, 165-171.

[17] Rizwana H., Alwhibi M.S., Khan F., Soliman D.A., Chemical composition and antimicrobial activity of Eruca sativa seeds against pathogenic bacteria and fungi, J. Anim. Plant. Sci., 2016, 26, 1859-1871.

[18] Boutemak K., Chekirine A., Tail G., Phytochemical screening, antioxidant and insecticidal activities of Ajuga iva, Int. J. Biol. Med. Sci., 2016, 1, 1-5.

[19] Esmaeili A., Moaf L., Rezazadeh S., Ayyari M., Antioxidant and antibacterial activity of various extracts of Malcolmia africana (L.) R. Br., Zahedan J. Res. Med. Sci., 2014, 16, 6-11.

[20] Karakoca K., Ozusaglam M., Cakmak Y., Erkul S.K., Antioxidative, antimicrobial and cytotoxic properties of Isatis floribunda Boiss. ex Bornm. extracts, EXCLI J., 2013, 12, 150167.

[21] Lindsay J., Laurin D., Verreault R., Hebert R., Helliwell B., Hill G.B., et al., Risk factors for Alzheimer's disease: a prospective analysis from the Canadian Study of Health and Aging, Am. J. Epidemiol., 2002, 156, 445-453.

[22] Salazar-Martinez E., Willett W.C., Ascherio A., Manson J.E., Leitzmann M.F., Stampfer M.J., et al., Coffee consumption and risk for type 2 diabetes mellitus, Ann. Intern. Med., 2004, 140, 1-8.

[23] Ranheim T., Halvorsen B., Coffee consumption and human health: beneficial or detrimental? Mechanisms for effects of coffee consumption on different risk factors for cardiovascular disease and type 2 diabetes mellitus, Mol. Nutr. Food Res., 2005, 49, 274-284.

[24] Alqasoumi S., Carbon tetrachloride-induced hepatotoxicity: protective effect of "Rocket" Eruca sativa L. in rats., Am. J. Chinese Med., 2010, 38, 75-88.

[25] Omri H.A., Mosbah H., Majouli K., Hlila M.B., Jannet H.B., Flamini G., et al., Chemical composition and biological activities of Eruca vesicaria subsp. longirostris essential oil, Pharm. Biol., 2016, 54, 2236-2243.

[26] Rani I., Akhund S., Suhail M., Abro H., Antimicrobial potential of seed extract of Eruca sativa, Pak. J. Bot., 2010, 42, 29492953.

[27] Davis P.H., Mill R.R., Tan K., Flora of Turkey and the East Aegean Islands, volume 10, Edinburgh University Press, Edinburgh, 1988.

[28] Caponio F., Alloggio V., Gomes T., Phenolic compounds of virgin olive oil: influence of paste preparation techniques, Food Chem., 1999, 64, 203-209.
[29] Bauer A.W., Kirby W.M.M., Sherris J.C., Turck M., Antibiotic susceptibility testing by a standardized single disk method, Am. J. Clin. Pathol., 1966, 45, 493-496.

[30] CLSI, Methods for dilution antimicrobial susceptibility test for bacteria that grow aerobically; approved standard, 6th ed., National Committee for Clinical Laboratory Standards, Philadelphia, 2003.

[31] CLSI, Performance standards for antimicrobial susceptibility testing, 16th informational supplement, National Committee for Clinical Laboratory Standards, Philadelphia, 2006.

[32] Brand-Williams W., Cuvelier M.E., Berset C., Use of a free radical method to evaluate antioxidant activity, LWT-Food Sci. Technol., 1995, 28, 25-30.

[33] Oliveira R., Lima E.O., Vieira W.L., Freire K.L., Trajano V., Lima I.O., et al., Estudo da interferência de óleos essenciais sobre a atividade de alguns antibióticos usados na clínica, Rev. Bras. Farmacogn., 2006, 16, 77-82.

[34] Widsten P., Cruz C.D., Fletcher G.C., Pajak M.A., McGhie T.K., Tannins and extracts of fruit by products: Antibacterial activity against foodborne bacteria and antioxidant capacity, J. Agric. Food Chem., 2014, 62, 11146-11156.

[35] Yıldırım I. and Kutlu T., Anticancer Agents: Saponin and Tannin. Int. J. Biol. Chem., 2015, 9, 332-340.

[36] Namiki M., Antioxidants/antimutagens in food, Crit. Rev. Food Sci. Nutr., 1990, 29, 273-300.

[37] Chung K.T., Wong T.Y., Wei C.I., Huang Y.W., Lin Y., Tannins and human health: a review, Crit. Rev. Food Sci. Nutr., 1998, 38, 421-464.

[38] Rosa E.A., Silva B.C., Silva F.M., Tanaka C.M.A., Peralta R.M., Oliveira C.M.A., et al., Flavonoides e atividade antioxidante em Palicourea rigida Kunth, Rubiaceae, Rev. Bras. Farmacogn., 2010, 20, 484-488.

[39] Joshi R., Gangabhagirathi R., Venu S., Adhikari S., Mukherjee T., Antioxidant activity and free radical scavenging reactions of gentisic acid: in-vitro and pulse radiolysis studies, Free Radic. Res., 2012, 46, 11-20.

[40] Razavi S.M., Zarrini G., Zahri S., Ghasemi K., Mohammadi S., Biological activity of Crambe orientalis L. growing in Iran, Pharmacognosy Res., 2009, 1, 125-129.

[41] Grosso C., Vinholes J., Silva R.S., Pinho P.G., Gonçalves R.F., Valentão P., et al., Chemical composition and biological screening of Capsella bursa-pastoris, Rev. Bras. Farmacogn., 2011, 21, 635-643. 